\title{
Práticas docentes e cotidianos escolares: análise sobre os usos e não usos das mídias digitais
}

Teaching and everyday school practices: analysis on the uses and non-uses of digital media

Leandro Marlon Barbosa Assis ${ }^{1}$ Alexandre Farbiarz ${ }^{2}$

\section{Resumo}

Este artigo busca compreender as mudanças nos costumes e comportamentos no cotidiano escolar, a partir da inserção das mídias digitais, em especial no que se refere à formação para a reflexão crítica do educando, com foco na interface da Comunicação com a Educação pela perspectiva da Educação Crítica para as Mídias. A abordagem teórica se baseia principalmente nos escritos de Paulo Freire e na revisão bibliográfica da área sob a perspectiva de diferenciação entre o conceito de mídias digitais e de tecnologia. Para a elaboração deste trabalho, foram entrevistados 10 educadores em três escolas da Rede Estadual do Estado do Rio de Janeiro e, ainda, realizada a Pesquisa Participante nos cotidianos para fundamentação da observação. Com base na Análise de Conteúdo das entrevistas, percebeuse que os educadores praticam um uso irrefletido das mídias no cotidiano escolar. Entretanto, destaca-se aqueles que, mesmo sem recursos, refletem sobre seus cotidianos e procuram fomentar e fortalecer o desenvolvimento de cidadãos críticos.

\footnotetext{
${ }^{1}$ Mestre em Mídia e Cotidiano pela Universidade Federal Fluminense (UFF). Especializando em Docência no século XXI (IFF). Bacharel em Jornalismo (UFRRJ) e Licenciado em História (UFRRJ).

2 Doutor em Design pela Pontificia Universidade Católica do Rio de Janeiro (PUC-RJ). Mestre em Educação pela Universidade de São Paulo (USP). Especialista em Administração pela PUC-RJ. Docente do Programa de Pós-Graduação em Mídia e Cotidiano do Departamento de Comunicação Social da UFF.

Interfaces da Educ., Paranaíba, v.11, n.32, p. 688 - 710, 2020
} 
Palavras-Chave: Educação Crítica para as Mídias. Prática Docente. Mídias Digitais. Cotidiano Escolar.

\section{Abstract}

This article seeks to understand the changes in customs and behaviors in school everyday life, from the insertion of digital media, focusing on the critical reflection of the student, with a focus on interface of Education with the perspective of Critical Education for Media. The theoretical approach is based mainly on the writings of Paulo Freire and the bibliographic review of the interface area under the perspective of differentiation between the concept of digital media and technology. For the elaboration of this work, 10 educators were interviewed in three schools of the State Network of the State of Rio de Janeiro and, also, the Participant Research was carried out in the locus of their everyday life to substantiate the observation. Based on the Content Analysis of the interviews, it was noticed that educators practice an unthinking use of the media in the school everyday life. However, we highlight those who, even without resources, reflect on their everyday lifes and seek to encourage and strengthen the development of critical citizens.

\section{Keywords}

Critical Media Education. Teaching Practice. Digital Media. Everyday life school.

\section{Introdução e marco teórico}

O cotidiano escolar, posto dentro de um sistema capitalista baseado no consumo para satisfação de prazeres (BAUMAN, 2001) e baseado nos estudos de Heller (2016) e Kosik (1976), é pensado como o espaço para que o conhecimento propicie uma tomada de posição a partir do exercício da reflexão sobre a produção constante, volumosa e rápida das mídias na contemporaneidade. Logo, é preciso compreender o cotidiano escolar como um dos múltiplos cotidianos (CANDAU, 2011) existentes na sociedade e, por conta disto, não podendo se dissociar das relações muitas vezes antagônicas 
estabelecidas na vida social. Assim, compreender os olhares sobre estes conflitos/disputas sociais é a essência da teoria reflexiva da prática social sobre o cotidiano ao qual o presente trabalho -se alinha.

Desse modo, a formação dos educadores deveria se orientar para a reflexão crítica e, em especial, sobre como as mídias estão penetrando na prática educativa. Alinhado a isso, precisaria, também, evitar que a inserção das "tecnologias" no ambiente escolar se desse por um viés de prótese (SODRÉ, 2012) para substituir o educador ou entreter o estudante.

"Mídias" e "tecnologias" aparecem constantemente no corpo do presente trabalho e optamos pela utilização da primeira por compreendermos que são "[...] dispositivos técnicos de comunicação e produção de sentidos [...] [para] novos modos de perceber a realidade, de aprender, de produzir e difundir conhecimentos e informações" (BELLONI, 2018, p. 449). Deste modo, ao alinharmos a interpretação adotada para mídias com sua vertente digital, procuramos estabelecer um recorte que permita identificar, “[...] qualquer mídia que utilize, como meio, um computador ou equipamento digital para criar, explorar, finalizar ou dar continuidade a um projeto que tem como suporte a internet, em comunicação on-line ou off-line" (ALBURQUEQUE; BRITO, 2018, p. 452). Esta compreensão se dá pela forma naturalizada pelo senso comum de que as escolas necessitam de "tecnologias", como um simples produto afastado da intencionalidade humana (MILL; BERTOLDO, 2018, p. 597).

Portanto, para ocorrer uma melhoria no ensino, as politicas públicas que orientam as reformas pedagógicas deveriam buscar o desenvolvimento crítico dos educandos, e precisariam migrar, em nossa compreensão, da "tecnologia" para as "mídias digitais". Como exemplo, os materiais divulgados que veiculam as necessidades de inserção tecnológica acabam por se orientar mais pelos modos de usar do que pela reflexão sobre as disputas hegemônicas pelo poder que circundam o desenvolvimento dessas tecnologias. Como analisam Selma Pimenta e Umberto Pinto (2013), precisamos tornar o processo produtivo capitalista mais próximo dos estudantes para que, dentro da sociedade, se possa pensar e debater Interfaces da Educ., Paranaíba, v.11, n.32, p. 688 - 710, 2020 
transformações sociais enquanto projeto de futuro, ou seja, apropriar-nos da lógica produtiva enquanto discurso para que reconheçamos os modos de fazer hegemônico e, ao fim, o possamos subverter.

A proposta pedagógica das imagens midiatizadas, então, pode ser compreendida por atuar pelo desejo de se expressar "[...] como memória afetiva de uma cultura, um substrato ideológico mantido pela comunidade" (MORAES, 2009, p. 29), ou seja, perceber a ideologia do consumo posta pelo espetáculo midiático (KELLNER, 2004), enquanto uma retórica para mascarar uma dominação, nos faz perceber que, sendo uma construção para manutenção desta sociedade capitalista, se expressa nas diferentes práticas e seduções hegemônicas (MORAES, 2009; Id., 2010), em especial na escola oferecida como "moderna" por ter uma sala cheia de "tecnologias".

Ao ressaltar esses pontos, constatamos o afastamento dos jovens do espaço de produção do conhecimento institucionalizado e o movimento de se silenciar essas mesmas vozes dentro das salas de aula por parte dos professores (FREIRE, 2015b). Neste sentido, os educandos não têm como se reconhecer como potenciais produtores do saber e, menos ainda, reconhecer a escola e os educadores como aqueles que podem auxiliá-los na produção de conhecimento através das mídias digitais (BUCKINGHAM, 2005).

Desbravando esta seara, portanto, Ismar Soares (2011) argumenta que esses macrocampos (Educação e Comunicação) já se relacionam e estabelece a importância do pensamento latino na construção de uma área realmente ativa e integrada. Em outras palavras, a escola, dentro do pensamento de Paulo Freire (2015a, p. 45), não deveria ter “[...] medo de conviver com eles [meios de comunicação], chegando mesmo até, risonhamente, a dizer: 'vem cá, televisão, me ajuda! Me ajuda a ensinar, me ajuda a aprender!', não?”. Por esta compreensão, conforme inda relata Soares (2000), a história nos ensina que tanto a Educação quanto a Comunicação, ao serem instruídas pela racionalidade moderna, tiveram seus campos de atuação demarcados, no contexto do imaginário social, como espaços independentes, aparentemente neutros, cumprindo funções específicas: a Educação administrando a transmissão do saber necessário ao desenvolvimento social, Interfaces da Educ., Paranaíba, v.11, n.32, p. 688 - 710, 2020 
quase sempre com os rumos ditados pelo Mercado; e a Comunicação responsabilizando-se pela difusão de informações, pelo lazer popular e pela manutenção do sistema produtivo através da publicidade. No entanto, a partir do pensamento latino, a aproximação foi constatada graças à contribuição teórico-prática de filósofos da Educação como Célestin Freinet e Paulo Freire; ou da Comunicação, como Jesús Martin-Barbero e Mario Kaplún.

Desta forma, perpassando os grandes eixos teóricos da interface, as atribuições de Media Education, elaboradas na UNESCO, são próximas ao que Melo e Tosta (2008) consideram como as associações mais evidentes da Comunicação e da Educação, como, por exemplo, a leitura crítica da mídia e a consideração dos saberes a partir da escola e de suas experiências pessoais. Noutra perspectiva, David Buckingham (2005), pesquisador britânico, utiliza a denominação Media Literacy para explicar seu entendimento de como a Comunicação e a Educação se encontram. Para ele, o educador não pode ser compreendido como aquele que traz o saber aos estudantes. Ou seja, o papel do educador será o de contribuir para que se desenvolva "[...] a capacidade de acessar, compreender e criar comunicações em variados contextos"1 (Ibid., p. 2) [Tradução nossa]. Contudo, o que pode aparentar similaridades é contestado por Divina Frau-Meigs (2006, p. 20), por acreditar se tratarem de elementos distintos. Para ela, "Media Education, então, é o processo de ensinar e aprender sobre mídia; Media Literacy é o resultado - o conhecimento e habilidades que os alunos adquirem"2 [Tradução nossa]. Ou seja, Media Education é o processo de ensino que parte do educador com a finalidade específica de ajudar na compreensão crítica do mundo e não só para servir de instrumental tecnológico para determinadas disciplinas escolares.

\footnotetext{
1 "the ability to access, understand and create communications in a variety of contexts" [Texto original]

2 "Media Education, then, is the process of teaching and learning about media; Media Literacy is the outcome - the knowledge and skills learners acquire" [Texto original]
}

Interfaces da Educ., Paranaíba, v.11, n.32, p. 688 - 710, 2020 
Abandonando a busca por um batismo dessa área acadêmica, existem em ambas as definições, a compreensão de que o pensamento crítico sobre os meios deve ser aprofundado como mote para o desenvolvimento de uma sociedade crítica e democrática. E é nesse ponto que reside nossa perspectiva para a prática docente. Entretanto, Mario Kaplún (2011) argumenta que existe um problema no cotidiano escolar e que este reside na massificação do ensino, onde teria restado menos espaço para a comunicação e a troca de saberes entre os estudantes. "Mas não só menos espaço: também menos interesse e menos vontade para propiciá-lo, menos consciência do alcance do diálogo, como componente necessário da ação educativa" (Ibid., p. 178). Nesse sentido, Roberto Aparici (2014) completa o entendimento da proposição de Kaplún (2011) ao sintetizar que a experiência de vida dos educandos é ignorada na proposição dos conteúdos e na elaboração dos ambientes escolares.

Daniel Castillo (2014) afirma, em tom otimista, que o desenvolvimento tecnológico permite o rompimento com o discurso dominante por existir uma rede conectada de saberes que se acessa a todo o momento para se conhecer uma infinidade de informações. Para o pensador, "[...] as redes de aprendizagem põem em jogo todos esses elementos: participação, colaboração, ativismo cidadão, criação coletiva e alianças voluntárias" (Ibid., p. 55). Contudo, em um ponto de inflexão, Aparici (2014) - em consonância ao pensado por Sodré (2012) - sinaliza que a tecnologia por si só não significa uma mudança, pois "[...] muitas das experiências educativas e comunicativas que recorrem às tecnologias digitais não deixam de ser gutenberguianas por usarem a web, já que continuam repetindo os mesmos modelos análogos do século passado" (Ibid., p. 35).

A reflexão acima pode ser sistematizada através do entendimento de Heller (2016) de que não existe uma objetividade natural que condicione o homem, mas uma social. Para a autora, a objetividade social contribui para a essência humana na participação da atuação coletiva. Desse modo, seu pensamento é baseado no sentido marxista de que a coletividade é composta pelos valores do humano - trabalho, sociabilidade, universalidade, Interfaces da Educ., Paranaíba, v.11, n.32, p. 688 - 710, 2020 
consciência e liberdade. Em suma, o humano está posto na superficialidade do que é a vida cotidiana de modo que, somente com a reflexão, poderia ser aprofundada ou suspensa. Portanto, perceber a necessidade de um trabalho em conjunto entre educadores e educandos é a chave para a transformação social e é aqui que residiria a potência das mídias digitais pensada por nosso projeto de pesquisa.

As propostas de Paulo Freire (1967), Mario Kaplún (2014) e Daniel Prieto Castillo (2014), deste modo, caminham com a dialogia, como oposição ao modelo educacional operado nas escolas tradicionais e bancárias. Assim, os estudos sobre a interface entre a Comunicação e a Educação caminhariam, em nossa interpretação, como uma quebra do padrão senhorial do ensino (tanto no sentido conteudista quanto no sentido mercadológico) e defenderia o debate como forma de construir saberes - pela dialogia para a intervenção social.

Praticar a interface, ao nosso ver, requer utilizar mídias digitais para o exercício da crítica e da reflexão sobre as disputas hegemônicas ${ }^{3}$. Em seguida é preciso explicitar o funcionamento dessas batalhas para que seja possivel decodificar seus discursos e, assim, garantir o pleno exercício da leitura crítica por parte de todos os envolvidos no processo iniciado no cotidiano escolar.

Compreendendo assim, a existência de linhas de estudo tecnicistas que priorizem o uso ou aperfeiçoamento tecnológico dos educadores, pautamo-nos pela formação enquanto ato contínuo de aprendizagem (FREIRE, 2015b). Observamos, portanto, que utilizar das mídias digitais é um exercício contínuo de se aperfeiçoar para conseguir, em conjunto aos educandos, ler/perceber o cotidiano midiatizado. Ou seja, "[...] o indivíduo é

\footnotetext{
3 Como exemplo, mencionamos os relatos de uma professora de Filosofia entrevistada: descobrir os interesses da turma, no campo musical. A partir disso, solicitar exemplos audiovisuais sobre os gêneros e, a partir da análise deles, iniciar debates sobre estética, construção linguística, segregações socioespaciais e relacionar com a indústria que se retroalimenta dessa produção. Como a professora relata, isso permite que nos aproximemos dos estudantes e, também, discutamos sobre os conteúdos de maneira mais prática e menos teórica - como sinaliza Freire (2015b) e diversos autores (BUCKINGHAM, 2005, SOARES, 2002; MORAES, 2009) como sendo o caminho para a reflexão e, por conseguinte, a suspensão do cotidiano (HELLER, 2016).
}

Interfaces da Educ., Paranaíba, v.11, n.32, p. 688 - 710, 2020 
inteligente porque ele faz. As tecnologias, como subprodutos da técnica, ganham, assim, nova dimensão, representando a evolução ou o retrocesso do modo de o ser humano estar no mundo" (SOARES, 2014, p. 22). Neste sentido, a "Educação Crítica para as Mídias", enquanto proposta interpretativa, parte de Douglas Kellner e Jeff Share (2008), quando propõem uma educação para a leitura crítica da mídia e defendem a "[...] alfabetização crítica [...] [sobre] [...] uma ampla variedade de formas de cultura midiática, informações e tecnologias da comunicação [...]" (Ibid., p. 687), sem esquecer do processo de alfabetização formal e digital que deve avançar no país.

\section{Metodologia}

A metodologia da pesquisa que sustenta este artigo englobou como métodos a Pesquisa Participante (PERUZZO, 2003; BRANDÃO, BORGES, 2007; THIOLLENT, 2009) e a Análise de Conteúdo (BARDIN, 1977), ampliando a metodologia da qual os dados foram retirados, conforme a Figura 1. A escolha dos métodos citados permitiu consolidar a compreensão do que se espera da prática docente com as mídias digitais a partir das fundamentações acadêmicas e governamentais e, assim, relacionar a prática dos educadores no cotidiano escolar, no que se refere à utilização das mídias digitais neste mesmo cotidiano. 
Figura 1 - Mapa metodológico da pesquisa

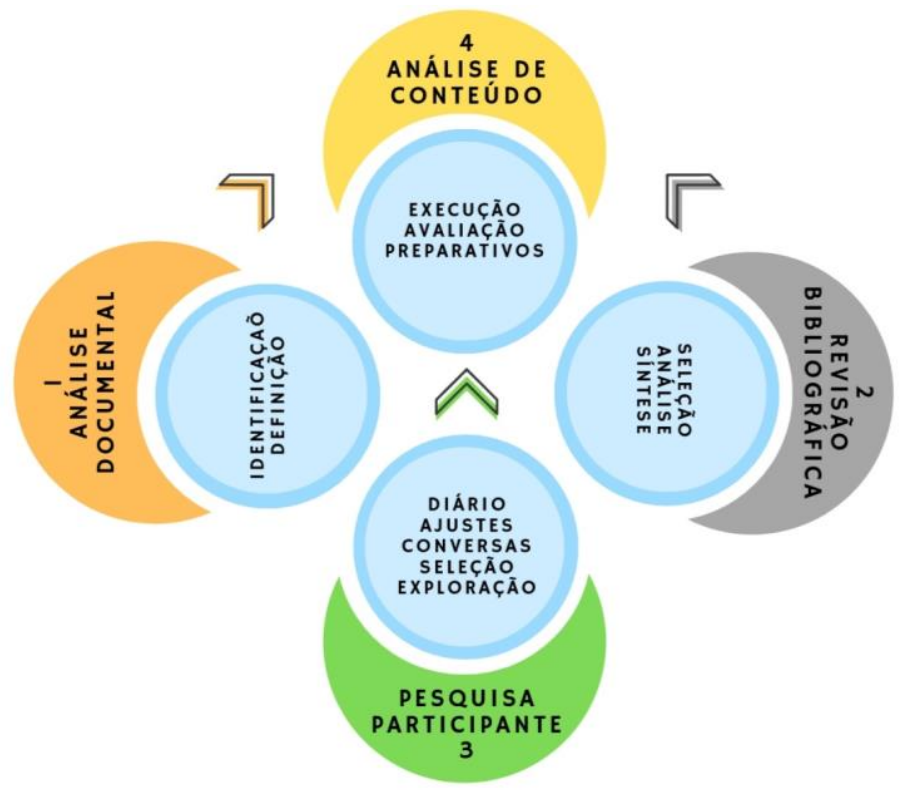

Fonte: Elaborado pelo autor.

A Pesquisa Participante foi utilizada como metodologia auxiliar na compreensão das nuances que compõem as escolas, apresentadas através das práticas docentes mais ou menos relacionadas com a reflexão crítica na promoção do uso das mídias digitais. Este processo, conforme indica Peruzzo (2003), parte de uma pesquisa bibliográfica e requer (a) "presença constante do observador no ambiente"; (b) o compartilhamento "de modo consciente e sistematizado das atividades do grupo"; e (c) a possibilidade de atingir o sentido das ações do outro. Dessa forma, no campo da pesquisa, foi explicado inicialmente, em reuniões, a intenção em observar a rotina escolar e, quando possivel, em entrevistar os participantes que se dispusessem a participar.

Portanto, a observação de campo se construiu sob a perspectiva da metodologia apresentada por Peruzzo, e se colocou como necessária para ofertar ao processo de pesquisa e aos leitores a compreensão de como os agentes da pesquisa (entrevistador/observador e entrevistados/observados) se comportavam como personagens ativos (THIOLLENT, 2009) dos cotidianos nos quais estavam inseridos. Isto posto, alinhamos os encaminhamentos de Peruzzo (2003) com os de Brandão e Borges (2007) e com o que Demo (1982, 
p. 81-82) estabelece como sendo a "exploração geral da comunidade" da pesquisa prática. Assim, acreditamos que conseguiremos "fazer um levantamento da situação, formular reivindicações e ações" (THIOLLENT, 2009 , p. 23) para cruzar o que os educadores sabem de sua prática cotidiana com o que os especialistas observam da temática no campo teórico (Ibid., p. 73) e, assim, analisar suas respostas.

A observação de campo foi realizada entre os dias 18 de outubro de 2017 e 06 de julho de 2018 em duas escolas estaduais do estado do Rio de Janeiro: a primeira, Escola A, localizada em São João de Meriti; e a segunda, Escola B, localizada em Campos dos Goytacazes (Tabela 1). Assim, os relatos apresentados neste artigo proveem do universo de 23 visitas às escolas e da observação constante das salas dos professores, dos corredores escolares e das conversas informais com os membros das comunidades escolares em paralelo às entrevistas realizadas.

Tabela 1 - Resumo do período e número de visitas para PP

\begin{tabular}{ccc|} 
Escola & Periodo & Número de visitas \\
A & $18 / 10 / 2017-$ & 07 \\
& $08 / 12 / 2017$ & \\
B & $27 / 03 / 2018-$ & 16 \\
Total & $21 / 06 / 2018$ & $\mathbf{2 3}$ \\
\hline
\end{tabular}

Fonte: Elaborado pelo autor.

$\mathrm{Na}$ Escola A, um convite inicial às entrevistas foi enviado em outubro de 2017. Obtivemos retornos espaçados durante o mês de novembro, sendo a maior parte delas realizadas na semana de provas do último bimestre, em dezembro, pela disponibilidade de horários. Foram realizadas entrevistas com seis educadores e uma orientadora pedagógica, descartada da análise de conteúdo pela busca de homogeneidade do corpus, mas considerada pela apresentação das impressões sobre o cotidiano daquela realidade. Na Escola B, em sequência, o convite foi enviado em abril de 2018 e em poucos dias obtivemos retorno dos educadores, resultando em quatro entrevistas que ampliaram as interpretações possíveis do tema de pesquisa. 
A seleção dos entrevistados para a pesquisa, portanto, foi estabelecida a partir da posição mencionada por Thiollent (2009), que valoriza os "critérios de representatividade qualitativa", ou seja, recorremos ao convite aberto às comunidades escolares para criar "amostras intencionais". A justificativa para esta abordagem se estabelece pela compreensão de que para se debater a prática docente, os educadores deveriam, de antemão, se mobilizar por si mesmos para a reflexão ou o interesse. Portanto, nossa ênfase segue os aspectos qualitativos além de ser regida pelas conversas com os participantes da pesquisa.

Tendo obtido a anuência e feito o contato, foi aplicado o instrumento da entrevista semiestruturada com os voluntários para propiciar posteriormente a Análise de Conteúdo. Dessa forma, as perguntas aplicadas aos educadores foram elaboradas para obter informações sobre o problema de pesquisa, como Lakatos e Marconi (2003) sintetizam. Assim, as entrevistas foram realizadas após algumas medidas (LAKATOS, MARCONI, 2003, p. 199), cabendo destaque para: (1) o planejamento prévio para se ter o objetivo a ser alcançado por elas; (2) o conhecimento prévio do entrevistado, por meio de conversas informais e da observação de campo; (3) a oportunidade da entrevista e (4) as condições favoráveis para realização, especialmente de modo a não atrapalhar o cotidiano escolar; (5) a preparação específica que consiste na elaboração do roteiro de questões.

Destaca-se, então, o conjunto de sete horas de entrevistas com os educadores da Escola A e da Escola B, transcritas em 93 páginas, para serem realizadas as análises propostas até o momento. Para este trabalho, a cada respondente foi atribuído um código identificador ${ }^{4}$ com o objetivo de permitir a organização da análise proposta por esta pesquisa e o anonimato dos mesmos. Fundamentados em Bardin (1977), dividimos as respostas dos

\footnotetext{
${ }^{4}$ A saber: a escola da qual o entrevistado fazia parte (A ou B), o número de matrículas e carga horária de trabalho semanal, a disciplina de ingresso na rede, a idade, o tempo em exercício do magistério e seu gênero. Por exemplo, EA/1(40)/LEI/42/23/F é uma professora de 42 anos que trabalha há 23 anos na sala de aula. Ela é concursada em Língua Estrangeira - Inglês e tem uma matrícula de $40 \mathrm{~h}$ semanais. Ela trabalha na escola A.
}

Interfaces da Educ., Paranaíba, v.11, n.32, p. 688 - 710, 2020 
profissionais em 160 listas separadas por entrevistado e, em seguida, por perguntas respondidas.

Deste material, foram elaboradas 16 listagens reunindo, cada uma, todas as respostas dadas a uma mesma pergunta como forma de compor o corpus da análise. Ainda nesta etapa, eliminamos duas listagens por considerar menções quantitativas imprecisas dos respondentes ${ }^{5}$. Portanto, 14 listagens foram utilizadas para realizar a Análise de Conteúdo e formaram o corpus final da pesquisa com um total de 67 páginas a serem utilizadas na categorização dos dados. Assim, as listas mencionadas permitem agrupar as respostas e classificá-las a partir de categorias (educador, educando, escola, governo e família), subcategorias (prática, participação, apoio, interesse, compreensão e outros) e subsubcategorias (geral, crítica e mídias digitais).

Concluindo a etapa da definição de categorias, indicamos a direção das respostas como sendo favoráveis; desfavoráveis ou neutras. Conforme sinaliza Bardin (Ibid., p. 111), "a ponderação da frequência traduz um carácter quantitativo (intensidade) ou qualitativo: a direção". Neste ponto, referente à intensidade e à direção, os estudos de Charles Osgood, a partir das observações de Bardin (1977), fornecem elementos para a construção de perfis a partir de frequências em escalas bipolares como as elencadas até aqui. Buscamos identificar, então, as atitudes dos educadores em relação às mídias digitais. Baseando-nos em dois critérios (direção e intensidade), temos um polo negativo [-3] gradativamente tendendo ao neutro [0] e passando ao outro polo, positivo [+3] - o que gera uma escala de sete pontos, onde podemos avaliar simultaneamente a bipolaridade semântica da Unidade de Registro e o grau de intensidade desta direção.

\footnotetext{
${ }^{5}$ As duas perguntas não abordadas nas listas que compõem o corpus da pesquisa foram "sua escola tem relação com o Facebook, Instagram ou outras mídias? Se sim, como funcionam?" e "do total de professores da sua escola, quantos você sabe que utilizam tecnologias digitais em suas aulas?".
} 


\section{Análise e resultados}

\section{Apresentando o corpus}

Ao sintetizarmos as entrevistas em tabelas, percebemos algumas informações preliminares (Tabela 2) que permitem a constatação de que, quando comentando suas práticas cotidianas, os educadores, apesar de terem uma compreensão levemente negativa $[-15 /-0,2]^{6}$, foram positivos [119/1,5], especialmente pela reflexão sobre suas práticas ${ }^{7}[119 / 0,9]$. Portanto, podemos inferir que eles acreditam que fazem o possivel para assegurarem um trabalho bem feito, ficando impedidos/desestimulados pela falta de apoio [-47/-1,9] provido por parte do governo [-86/-1,9]; pela falta de interesse [-17/-0,4] dos educandos [-167/-0,9]; pela falta de apoio [-21/-0,3] das escolas [-60/-0,3] no cotidiano escolar; e pela falta de apoio [-2/-0,4] das famílias $[-23 /-1]$.

Este cenário, então, permite que façamos a inferência de que, excetuando sua atuação dentro das escolas, eles acreditam que todo o conjunto da comunidade escolar tende a prejudicar o seu trabalho. Dentro dessa análise, o governo é aquele com pior grau de intensidade, mesmo não se apresentando dentro das três categorias mais citadas. Portanto, ao considerarmos os dados expostos na Tabela 2, ressaltamos as aproximações e os distanciamentos existentes entre as Unidades Escolares e os diversos níveis de observações propostos nesta etapa.

\footnotetext{
${ }^{6}$ Ao longo das páginas que seguem, serão apresentados os valores de DS e DSM de forma a possibilitar a compreensão por parte dos leitores sobre os dados que fundamental as análises feitas. Portanto, sempre que aparecer esta sequência entre colchetes, seu significado é de [DS/DSM]. Neste caso, o valor refere-se à subcategoria compreensão, não posta em tabela pela limitação do artigo.

7 "Prática" é uma subcategoria dentro de educadores. A escolha de se mencionar as subcategorias "compreensão" e "práticas" no corpo do texto se faz por ser o elemento de como os educadores se compreendem no geral e, ainda, sua prática.
}

Interfaces da Educ., Paranaíba, v.11, n.32, p. 688 - 710, 2020 
Tabela 2 - Extrato da Frequência, do $\mathrm{DS}^{8}$, do $\mathrm{DSM}^{9}$ e o percentual por amostragem (\%) da categoria

\begin{tabular}{|c|c|c|c|c|}
\hline Categoria & Frequência & DS & DSM & $\%$ \\
\hline \multicolumn{5}{|c|}{ Geral } \\
\hline Educador & 308 & 115 & 0,4 & 39,60 \\
\hline Escola & 222 & -60 & $-0,3$ & 28,53 \\
\hline Educando & 181 & -167 & $-0,9$ & 23,26 \\
\hline Governo & 45 & -86 & $-1,9$ & 5,78 \\
\hline Familia & 22 & -23 & $-1,0$ & 2,83 \\
\hline Total & 778 & -221 & $-0,3$ & 100 \\
\hline \multicolumn{5}{|c|}{ Escola A } \\
\hline Educador & 207 & 25 & 0,1 & 37,84 \\
\hline Escola & 152 & -56 & $-0,4$ & 27,79 \\
\hline Educando & 142 & -123 & $-0,9$ & 25,96 \\
\hline Governo & 32 & -62 & $-1,9$ & 5,85 \\
\hline Familia & 14 & -19 & $-1,4$ & 2,56 \\
\hline Total & 547 & -235 & $-0,4$ & 100 \\
\hline \multicolumn{5}{|c|}{ Escola B } \\
\hline Educador & 101 & 90 & 0,9 & 43,72 \\
\hline Escola & 70 & -4 & $-0,1$ & 30,30 \\
\hline Educando & 39 & -44 & $-1,1$ & 16,88 \\
\hline Governo & 13 & -24 & $-1,8$ & 5,63 \\
\hline Família & 8 & -4 & $-0,5$ & 3,47 \\
\hline Total & 231 & 14 & 0,1 & 100 \\
\hline
\end{tabular}

Fonte: Elaborado pelo autor.

Ao considerarmos os dados apresentados na Tabela 2, percebemos que as três categorias mais citadas (educador, escola e educando) são as mesmas em ambas as escolas, inclusive na mesma ordem e com percentuais de Frequência próximos, exceto a categoria educandos na Escola B. Continuando a observação preliminar a partir dos dados expostos, cabe destacar o Diferencial Semântico Médio (DSM) negativo da categoria governo nas duas UE em que foram realizadas as entrevistas.

8 O Diferencial Semântico (DS) significa a intensidade e a direção da resposta dada à pergunta, podendo variar de [-3] a [+3] numa escala de sete pontos, sendo o [0] sendo o ponto neutro ou ambíguo.

9 O Diferencial Semântico Médio (DSM) é obtido dividindo-se o total de DS pela Frequência. Admitindo-se que o DS varia de [-3] a [+3] em cada UR, o DSM indica como a categoria, ou as subcategorias e subsubcategorias, são avaliadas, proporcionalmente ao peso da Frequência (FARBIARZ; JOVANOVIC, 2002). 
Apesar de a categoria governo [45] ser aquela com o DSM mais negativo [-1,9], não aparece como a mais citada pelos entrevistados. Entretanto, ao sinalizarmos a predominância das três categorias, elas destoam, ainda, no que se refere ao Diferencial Semântico (DS) encontrado para o universo de entrevistas. Como se percebe, as categorias tendem a valores negativos enquanto que somente os educadores [115] se apresenta positivamente. Dessa forma, podemos estabelecer a premissa de que os entrevistados veem, conforme explicitado anteriormente, um ambiente educacional precarizado em contraposição à posição positiva quanto a si mesmos.

Assim, ao relacionarmos os dados absolutos do corpus da pesquisa podemos sintetizar que não é a Frequência pura das entrevistas que levaria à compreensão do cotidiano escolar - como a observação sobre a categoria governo demonstra. Noutras palavras, percebemos que, sim, temos três categorias que se sobressaem dentre as demais, mas que elas divergem quanto à qualidade das observações estabelecidas pelos entrevistados. Desta forma, podemos reforçar a inferência de que os educadores componentes do corpus da pesquisa veem que seu trabalho tende a ser prejudicado diante das demais categorias quando postas em comparação.

\section{Elixir e unguento}

Ao partirmos do cotidiano escolar, estamos mais bem fundamentados para conseguir compreender como são utilizadas as mídias digitais e a reflexão crítica na prática docente dos educadores na Rede Estadual do Rio de Janeiro. Das discussões estabelecidas no processo de pesquisa, podemos compreender os artificios das tecnologias a partir da imagem do elixir descrita por Ramon García (2012).

Ao passarmos, então, para a visão dos educadores entrevistados sobre a categoria educando, percebemos que predomina uma visão negativa sobre o processo de análise. Excetuando EA/1(40)/LEI/42/23/F, que vê uma ação advinda dos educandos no processo de buscarem saídas e informações críticas sobre as diversas questões da vida, e de EB/1(16)/FIL/37/8/F, que Interfaces da Educ., Paranaíba, v.11, n.32, p. 688 - 710, 2020 
vê pontos positivos na audácia dos estudantes, os educadores tendem a observar os jovens como indivíduos inertes ou absortos nas tecnologias e sem um processo reflexivo-crítico. Desta forma, ao analisarmos o papel da reflexão crítica na fala dos entrevistados, percebemos que, quando se referindo à sua condição de educador, apresentam sua compreensão [23/1,5] para a execução da prática $[39 / 1,8]$ cotidiana.

Neste sentido, podemos inferir que os educadores, quando refletindo sobre sua condição, tendem a compreender a importância da reflexão crítica no cotidiano escolar, exemplificando com algumas de suas práticas docentes, mas que, também, vivenciam as dificuldades desse processo educativo baseados em uma compreensão que rompa com a "educação bancária" (FREIRE, 2015) e tradicional que é praticada no Brasil (SAVIANI, 2013; Id., 2016; FRIGOTTO, 1984; BRANDÃO, 1985; PIMENTA, PINTO, 2013; MARTINS, 2016). Desta dialética, portanto, ressalta-se a fala de EA/1(16)/HIS/33/1/F/15 que, ao exemplificar sua proposta sobre como poderia desenvolver o senso crítico em turmas de sexto e sétimo anos, fica limitada pelos fatores externos ao cotidiano escolar, tais como a violência e o consumo de bebidas alcoólicas.

No cotidiano escolar, portanto, os relatos da Escola A se condensam na linha de que existe uma carência externa à escola (corroborada pelos relatos de EA/1(16)/HIS/33/1/F/15 e pela observação de campo) e, também, interna ao cotidiano das práticas docentes, em especial, a falta de conteúdos, como também ressaltou EA/1(16)/HIS/33/1/F, ou de equipamentos, como destacou EA/2(16/30)/GEO/55/10/M/13. Assim, fica em aberto como o processo crítico pode ser fomentado em um cotidiano escolar que: (a) não garanta o acesso às informações, por vias tecnológicas ou não; (b) não garanta a segurança dos direitos constitucionais às crianças e adolescentes de acesso à educação e formação (BRASIL, 1988; Id., 1996; Id.,1998; Id., 2000; Id., 2013); e (c) não propicie a reflexão e o pensamento crítico na forma da dialogia proposta por Freire (1967).

Como se percebe na Escola A, quando relacionam sua prática com o envolvimento dos jovens educandos, os educadores da Escola B associam o Interfaces da Educ., Paranaíba, v.11, n.32, p. 688 - 710, 2020 
desinteresse existente ao mau uso dos dispositivos móveis e das mídias digitais. Contudo, diferentemente do que ocorre na outra escola, eles propõe uma análise crítica que passa pelo ambiente familiar, pela aceleração do tempo e das informações presentes no pensamento de Citelli (2017).

\section{Discussão e considerações}

Ao ponderarmos sobre a naturalização de um discurso no senso comum quanto à necessidade de a escola da rede pública receber tecnologias para sua melhoria, percebemos que é através da prática docente reflexiva, crítica e dialógica que romperemos com a ideia de um saber que desconsidere os cotidianos dos educandos. Em sintese, podemos nos assumir enquanto pesquisadores e cidadãos engajados nas disputas hegemônicas do mundo através do debate constante a partir de nossa compreensão econômico-social e pela inserção crítica das mídias digitais na Educação - de modo político, como já sinalizaram Freire e Guimarães (2011) - para impedirmos a apatia e/ou desinteresse aos educandos, por considerálos sujeitos na escola.

Pensamos que, muitas vezes, a categoria educador descreve uma realidade como negativa por desconhecer ou por não perceber a relevância da utilização de tais instrumentos com um viés crítico - e, claro, seu afastamento do pensamento freiriano que guia esta pesquisa. Por outro lado, é evidente que a "culpa" pela não utilização crítica, ou mesmo a simples utilização sem profundidade, não deve recair somente sobre o profissional. Tanto o é que, mesmo não tendo alcançado uma Frequência elevada, a categoria governo foi aquela com o maior DSM em todos os niveis de análise, demonstrando o peso da falta de uma política pública que de fato propicie uma melhor formação profissional, condição salarial e estrutura de trabalho.

Como indicado por algumas respostas, o aparato legal, no que se refere ao uso e à formação docente, fica a desejar, indicando uma desconexão entre a lei escrita e o cotidiano escolar posto em prática aos educadores. Destarte, consideramos que o educador não é capaz de perceber os limites propostos pelo uso crítico das mídias digitais na sua prática Interfaces da Educ., Paranaíba, v.11, n.32, p. 688 - 710, 2020 
docente por ter ocorrido alguma falha em seu processo formativo e, também, pela inexistência de estrutura básica para tal. Este profissional não é formado para considerar a disputa de poder que ocorre na era da informação.

Assim, os educadores podem se inteirar e buscar a utilização das mídias digitais em suas práticas, mas sem o apoio da gestão pedagógica nas escolas e, por último, do governo, tendendo a ficarem desmotivados e, por conseguinte, reduzirem seu empenho profissional dentro das salas de aula. Portanto, ao cruzarmos as análises realizadas até aqui, podemos perceber que os costumes e comportamentos no cotidiano escolar vêm se alterando na mesma velocidade em que se altera a sociedade. Os jovens educandos de hoje diferem daqueles que estiveram nas salas dos primeiros dias dos educadores e, em conjunto, muitos dos educadores se apresentaram como os mesmos de antes, só que sem a motivação e a crença na melhora de sua profissão. Assim sendo, a precarização da profissão docente reforça as diferenciações socioeconômicas e não alcança os objetivos políticos postos nos documentos que regem a educação brasileira.

As duas escolas pesquisadas estão inseridas em um fluxo constante e de aumento exponencial de informações postas à disposição da sociedade. Deste modo, é perceptivel o predomínio de educadores que, embora sinalizem sua preocupação com a reflexão crítica, não o fazem quando suas práticas se vinculam às mídias digitais ou, ainda, não o fazem quando suas práticas docentes cotidianas silenciam a prática com mídias digitais e a reflexão em conjunto com educandos em um processo dialógico.

Vivenciando o cotidiano dos educadores nas escolas que acompanhamos, acreditamos que destacar as possibilidades práticas a partir da Educação Crítica para as Mídias não reduz a importância do relatado pelos respondentes, mas, tão somente, ressalta a potencialidade de que a utilização crítica das mídias digitais pode propiciar à prática docente - se, a prática regular já tiver rompido com as formas tradicionais de ensino. Salientamos, então, que não é a visão parcial de cada escola que fornece elementos para análise, visto que cada realidade escolar traz elementos Interfaces da Educ., Paranaíba, v.11, n.32, p. 688 - 710, 2020 
diferentes às possiveis interpretações de causas e efeitos da utilização das mídias digitais. Assim, a partir do cruzamento dos cotidianos escolares apresentados na pesquisa, ressaltamos que três pontos se mostram como de maior peso nesse processo: (1) a formação do educador; (2) a realidade em que está situada a escola; e (3) o apoio recebido da escola e do governo. Afirmamos tais pontos como preponderantes em virtude de que, quando não tendo a base teórica para sua prática, muitos educadores apresentam-se inseguros ou mascaram suas práticas com respostas que destoam do observado no dia a dia escolar. Essa diferenciação permite, portanto, perceber que, mesmo de origens díspares, há o mesmo padrão de comentários por parte dos educadores: (a) eles estão perdidos quanto ao uso das tecnologias; (b) eles recebem/consomem um amplo fluxo informacional; (c) eles têm desinteresse. Finalizando os pontos levantados, a falta de apoio ou incentivo para utilização das Mídias Digitais apontada pelos educadores sintetiza o abandono que sentem sobre suas práticas docentes: (1) sem um processo de discussão amplo sobre os rumos que se planejam para a educação na contemporaneidade; (2) sem um investimento efetivo em equipamentos para ampliar as possibilidades da prática docente; e (3) sem um acompanhamento pedagógico adequado para contribuir com o avanço de sua atuação profissional.

Os modelos apresentados para exercício de uma Educação Crítica para as Mídias, portanto, têm correlação para os propósitos da pesquisa, quando permitem avaliar a forma pela qual a prática docente se vincula à utilização das mídias digitais. Partindo da compreensão teórica sobre a interface entre os campos da Educação e da Comunicação, percebemos a importância e a urgência de uma formação crítica para o uso das mídias digitais.

Considerando a influência da categoria governo e da categoria educando no processo, já citados anteriormente, foi perceptivel que a prática docente pode propiciar uma formação mais crítica, mesmo quando sem as mídias digitais. O que pudemos perceber é que os educadores não reduzem sua prática docente ao desestímulo do governo em sua atuação. Porém, independente da escola, demonstram um preconceito sobre os educandos Interfaces da Educ., Paranaíba, v.11, n.32, p. 688 - 710, 2020 
que depende mais de fatores intrínsecos a eles do que de elementos do cotidiano escolar. Contudo, este não é o ponto central da pesquisa.

Procuramos, portanto, compreender, na prática desmotivada dos educadores e sem um sentido político, como as mídias digitais se inserem no cotidiano escolar. O uso irrefletido, como era de se esperar, apresenta-se como uma realidade das escolas por uma naturalização da utilização das mídias no dia a dia. Entretanto, cabe destaque a educadores que, mesmo sem os recursos para utilizar das mídias digitais, refletem sobre seus cotidianos e procuram fomentar e fortalecer o desenvolvimento de cidadãos críticos.

Assim, reconhecemos que cada educador traz consigo as experiências de seus cotidianos, porém defendemos que ele precisa ser um agente da transformação social. Sendo assim, mesmo que a direção escolar impeça, não promova ou não se importe com o desenvolvimento das habilidades expostas para uma educação do século XXI a partir da Educação Crítica para as Mídias, ele deve exercer seu papel social posto: formar cidadãos. É inspirar, respirar e seguir. Apesar do cenário conturbado, a pesquisa comprovou o que Certeau (2014) argumenta, quando afirma que há ações que subvertem as intenções postas por outros dentro dos cotidianos. Contudo, é deste ponto que pulsou o coração da pesquisa que se conclui: iniciar a caminhada para alcançar a utopia helleriana de uma sociedade de cidadãos críticos e que estejam sempre atentos às pseudoconcreticidades postas como modernas no uso das tecnologias nas escolas.

\section{Referências}

ALBURQUEQUe, G. A. Sa. de; BRITO, G. da S. Mídias digitais. In: MILL, D. (Org.). Dicionário crítico de educação e tecnologias e de educação a distância. Campinas: Papirus, 2018.

APARICI, R. Introdução: a educomunicação para além do 2.0. In: APARICI, R. Educomunicação para além do 2.0. São Paulo: Paulinas, 2014. p. 2944.

BARDIN, L. Análise de Conteúdo. Lisboa: Edições 70, 1977. 
BAUMAN, Z. Modernidade Liquida. Tradução de Plinio Dentzien. Rio de Janeiro: Jorge Zahar Ed., 2001.

BELlONI, M. L. Mídia-educação. In: MILL, D. (Org.). Dicionário crítico de educação e tecnologias e de educação a distância. Campinas: Papirus, 2018.

BRANDÃO, C. R. Educação popular. São Paulo: Brasiliense, 1985.

BUCKINGHAM, D. The Media Literacy of Children and Young People: a review of the research literature on behalf of Ofcom. Londres: Ofcom, 2005.

CANDAU, V. M. Magistério: construção cotidiana. Petrópolis: Vozes, 2011. CASTILLO, D. P. Construir nossa palavra de educadores. In: APARICI, Roberto. Educomunicação para além do 2.0. São Paulo: Paulinas, 2014. p. 45-58.

CERTEAU, M. de. A invenção do cotidiano: artes de fazer. Petrópolis: Vozes, 2014.

CITELLI, A. O. Educomunicação: temporalidades e sujeitos. In: CITELLI, A. O. Educomunicação - Comunicação e Educação: os desafios da aceleração social do tempo. São Paulo: Paulinas, 2017. p. 11-26.

FARBIARZ, A.; JOVANOVIC, V. A. Universidade-aluno: uma ponte em construção. Dissertação de Mestrado. São Paulo: Faculdade de Educação da USP, 2002.

FRAU-MEIGS, D. Media Education: A Kit for Teachers, Students, Parents and Professionals. Paris: L'exprimeur, 2006.

FREIRE, P. Educação como prática da Liberdade. Rio de Janeiro: Paz \& Terra, 1967.

FREIRE, P. Extensão ou Comunicação?. São Paulo: Paz \& Terra, 2011.

FREIRE, P. Política e educação. São Paulo: Paz \& Terra, 2014.

FREIRE, P. Ação cultural para a liberdade e outros escritos. São Paulo: Paz \& Terra, 2015a.

FREIRE, P. Pedagogia do Oprimido. São Paulo: Paz \& Terra, 2015b.

FREIRE, P.; GUIMARÃES, Sérgio. Educar com a midia: novos diálogos sobre educação. São Paulo: Paz \& Terra, 2011.

FRIGOTTO, G. Educação como capital humano: uma teoria social mantenedora do senso comum. São Paulo: Cortez, 1984. 
GARCÍA, R. I. C. TICs: entre o messianismo e o prognatismo tecnológico. In: APARICI, R. (Coord.). Conectados no ciberespaço. São Paulo: Paulinas, 2012.

HELLER, A. O cotidiano e a História. São Paulo: Paz \& Terra, 2016. KAPLUN, M. Processos educativos e canais de comunicação. In: CITELLI, A. O.; COSTA, M. C. C. Educomunicação: construindo uma nova área de conhecimento. São Paulo: Paulinas, 2011. p. 175-188.

KAPLUN, M. Uma pedagogia da comunicação. In: APARICI, R. Educomunicação para além do 2.0. São Paulo: Paulinas, 2014. p. 59-80. KELLNER, D. A cultura da mídia e o triunfo do espetáculo. São Paulo, Libero, a. VI, v. 6, n. 11, 2004.

KELLNER, D.; SHARE, J. Educação para a leitura crítica da mídia, democracia radical e a reconstrução da educação. In: Revista Educação e Sociedade. Campinas, v. 29, n. 104 - Especial, p. 687-715, out. 2008. Disponivel em: http://www.scielo.br/pdf/es/v29n104/a0429104.pdf. Acesso em: 12 fev. 2017.

KOSIK, K. Dialética do concreto. São Paulo: Paz \& Terra, 1976. LAKATOS, E. M.; MARCONI, M. de A. Fundamentos de metodologia científica. São Paulo: Atlas, 2003.

LAVILLE, C.; DIONNE, J. A construção do saber: manual de metodologia da pesquisa em ciências humanas. Tradução Heloisa Monteiro e Francisco Settineri. Porto Alegre: Artmed; Belo Horizonte: Editora UFMQ, 1999.

MARTINS, E. M. Todos pela educação? Como os empresários estão determinando a política educacional brasileira. Rio de Janeiro: Lamparina, 2016.

MELO, J. M. de; TOSTA, S. P. Mídia \& Educação. Belo Horizonte: Autêntica Editora, 2008.

MILL, D.; BERTOLDO, H. L. Tecnologia. In: MILL, D. (Org.). Dicionário crítico de educação e tecnologias e de educação a distância. Campinas: Papirus, 2018.

MORAES, D. de. Gramsci e as mutações do visível: comunicação e hegemonia no tempo presente. In: MORAES, D. de. Mutações do visivel: da comunicação de massa à comunicação em rede. Rio de Janeiro: Pão e Rosas, 2010.

MORAES, D. de. Imaginário social, hegemonia cultural e comunicação. In: MORAES, D. de. A Batalha da Mídia: governos progressistas e políticas de comunicação na América Latina e outros ensaios. Rio de Janeiro: Pão e Rosas, 2009.

Interfaces da Educ., Paranaíba, v.11, n.32, p. 688 - 710, 2020 
PERUZZO, C. Da observação participante à pesquisa-ação em comunicação: pressupostos epistemológicos e metodológicos. In: Congresso Brasileiro de Ciências da Comunicação, 26., 2003, Belo Horizonte. Anais... Belo Horizonte: Intercom, 2003.

PIMENTA, S. G.; PINTO, U. de A.. Apresentação. In: PIMENTA, S. G.; PINTO, U. de A. (Orgs.). O papel da escola pública no Brasil Contemporâneo. São Paulo: Edições Loyola, 2013.

SAVIANI, D. Da LDB (1996) ao novo PNE (2014-2024): por uma outra politica educacional. 5. ed. Campinas: Autores Associados, 2016.

SAVIANI, D. Vicissitudes e perspectivas do direito à educação no Brasil: abordagem histórica e situação atual. Educação e Sociedade, Campinas, 34, jun./set. 2013. p. 743-760. Disponivel em: http://www.scielo.br/scielo.php?script=sci_arttext\&pid=S0101$73302013000300006 \& l n g=e n \& n r m=$ iso, Acesso em: 03 abr. 2018.

SOARES, I. de O. Educomunicação: um campo de mediações. Comunicação \& Educação, Brasil, v. 19, set./dez., 2000, p. 12-24.

SOARES, I. de O. Educomunicação: o conceito, o profissional, a aplicação contribuições para a reforma do Ensino Médio. São Paulo: Paulinas, 2011.

SOARES, I. de O. Introdução à edição brasileira. In: APARICI, Roberto. Educomunicação para além do 2.0. São Paulo: Paulinas, 2014. p. 7-28. SODRÉ, M. Antropológica do espelho: uma teoria da comunicação linear e em rede. Rio de Janeiro: Vozes, 2012a.

THIOLLENT, M. Metodologia da pesquisa-ação. São Paulo: Cortez, 2009. 